\title{
THE EFFECTIVE INTERVENTION TO REDUCE HOSPITAL NURSE TURNOVER: A SYSTEMATIC REVIEW
}

\author{
Ivoni Pollatu, Puput Oktamianti
}

Faculty of Public Health, Universitas Indonesia, Depok, Indonesia

\begin{abstract}
Background: Employee turnover is one of the most serious issues in current hospital scenario. High turnover of nurses may affect the routine work flow of the hospitals.High turnover of nurses can bring about lot of negative effects to the organization such as dissatisfaction of the patients, impaired safety of the patients, loss of patients, and thereby reputation of the hospitals. As such, effective interventions are in need to reduce the nurse turnover in hospitals so as to maintain the high quality of health services delivered. This systematic review aimed at identifying effective interventions to reduce hospital turnover.

Subjects dan Method: A systematic review was conducted by searching databases from ProQuest, EBSCOhost, and Google Search on research articles publishedfrom 1990 to 2017. The searching keywords "intervention" AND "to reduce" AND "nursing turnover" AND "intention to stay" AND "hospital" resulted in 274 studies. These studies were sorted by the inclusion criteria: observational study, journal/ thesis/ dissertation, and full text. Finally, there were eight studies that could be reviewed.

Results: Effective intervention to reduce the nurse turnover in hospitals need consistent implementation by all stakeholders. The effective interventions included an organizational commitment to nurse career development (including promotion, continuing education, training), service-oriented leadership style, nurse involvement, need based-work management, and conflict management.

Conclusion: Effective interventions to reduce nurse turnover should include organizational commitment to nurse career development, service-oriented leadership style, participatory management, need based-work management, and conflict management.
\end{abstract}

Keywords: hospital, nurse, turnover, intervention, effective

Correspondence:

Ivoni Pollatu. Faculty of Public Health, Universitas Indonesia, Depok, Indonesia

Mid-International Conference on Public Health, 